\title{
Isolation, characterization and PCR multiplexing of microsatellite loci for a mite crop pest, Tetranychus urticae (Acari: Tetranychidae)
}

\author{
Laure Sauné*, Philippe Auger, Alain Migeon, Jean-Emmanuel Longueville, Simon Fellous and Maria Navajas
}

\begin{abstract}
Background: Tetranychus urticae is a highly polyphagous species with a cosmopolitan distribution that has the status of pest in more than 100 economically significant crops all over the world. Despite a number of previous efforts to isolate genetic markers, only a reduced set of microsatellite loci has been published. Taking advantage of the whole genome sequence of T. urticae that recently became available; we isolated and characterized a new set of microsatellite loci and tested the level of polymorphism across populations originating from a wide geographical area.

Results: A total of 42 microsatellite sequences widespread in the T. urticae genome were identified, the exact position in the genome recorded, and PCR amplification of microsatellite loci tested with primers defined here. Fourteen loci showed unambiguous genotype patterns and were further characterized. Three multiplex polymerase chain reaction sets were optimized in order to genotype a total of 24 polymorphic loci, including 10 previously published Tetranychus-specific loci. The microsatellite kits successfully amplified 686 individuals from 60 field populations for which we assessed the level of genetic diversity. The number of alleles per locus ranged from 3 to 16 and the expected heterozygosity values ranged from 0.12 to 0.81 . Most of the loci displayed a significant excess of homozygous and did not model the Hardy-Weinberg equilibrium. This can be explained by the arrhenotokous mode of reproduction of T. urticae.
\end{abstract}

Conclusions: These primers represent a valuable resource for robust studies on the genetic structure, dispersal and population biology of T. urticae, that can be used in managing this destructive agricultural pest.

Keywords: Tetranychus urticae, Spider mite, Microsatellite, Multiplex PCR

\section{Findings}

Tetranychus urticae (the two spotted spider mite) is a cosmopolitan and highly polyphagous species. This mite has been reported from about 1059 host plants and is a major pest for 100 crops [1]. Despite the worldwide distribution and high agricultural relevance of the species, the extent of its genetic diversity still lacks of information. The evolutionary history of T. urticae, while only partially explored, indicates high biodiversity. Analyses

*Correspondence: laure.saune@supagro.inra.fr INRA, UMR1062 CBGP, Campus International de Baillarguet, CS 30016, 34988 Montferrier-sur-lez Cedex, France based on MtDNA COI sequences split T. urticae populations in two clearly separated clades with $5 \%$ of nucleotide divergence [2]. This uncovered diversity and the broad relevance of the species, has motivated intensive efforts to isolate fine-resolution markers for population studies. Early screening of genomic libraries indicated an under-representation of microsatellite sequences in the mite genome [3]. Subsequent efforts to determine genetic markers led to the isolation and use of a reduced number of microsatellites $[4,5]$ and motivated population genetic studies. While the isolation by geographical distance had appeared as a major factor of population structure [6, 7]. The host plants where the mite develops seems to also 
have some influence. Genetic data from mites collected on citrus groves suggests some population differentiation between individuals collected on trees and weeds [8], while high level of dispersion among apple orchards tend to reduce genetic differentiation [9]. Genetic markers have also helped to further clarify taxonomic issues as the status of the red and green forms of T. urticae [6]. However, due to the limited number of markers used so far (usually five), the information remains limited to clearly understand the genetic diversity of the species and spots the need for an increased number of fine scale markers.

The whole genome sequence of $T$. urticae became recently available [10], facilitating the detection of additional microsatellite sequences. Some attempts to use cross-hybridizing primers to amplify Tetranychus species close to T. urticae have also been published [11]. The isolation and characterisation of a new set of microsatellite markers reported in this paper represents a valuable resource to deeper understand the biology of T. urticae. Estimates of gene flow and then of movements of individuals, to predict dissemination of genes involved in pesticide resistance, or to assess the impact of host plants as reservoirs (e.g. [8]), are a few examples of the questions that can be addressed using fine-scale markers, which should also help to manage mite populations of this important crop pest.

The isolation and characterization of the new set of primers was based on sequences of the T. urticae genome. All sequencing reads were collected with standard Sanger sequencing protocols on ABI 3730XL capillary sequencing machines at the Department of Energy Joint Genome Institute (DOE-JGI; Walnut Creek, CA, USA). The final assembly contains 640 scaffolds that cover $89.6 \mathrm{Mb}$ of the genome with a contig L50 of $212.8 \mathrm{~kb}$ and a scaffold L50 of $3.0 \mathrm{Mb}$ [10]. A total of 8,435 regions ranging from 413 to 720 bp were identified. Among them 546 and 1389 included di and tri-nucleotide repeats respectively (as analysed using QDD [12]). The exact position of the selected sequences was recorded according to the whole genome sequence from individual scaffolds of the T. urticae (London strain) genome available through GenBank under accession numbers HE587301 to HE587940 (see also http://bioinformatics.psb.ugent.be/orcae/overview/ Tetur).

Primers design was done with the program QDD [12]. Sequences longer than 80 base pairs (bp) and containing perfect microsatellites of at least five repetitions for any motif of 2-6 nucleotides were selected for further analyses. PCR primers were designed using QDD with the following stringent criteria: (1) target microsatellites had at least five repetitions, (2) length of PCR products were between 90 and $300 \mathrm{bp}$, (3) flanking regions did not contain either any homopolymer stretch of more than four bases or any di-hexa base pair motifs of more than two repetitions, (4) annealing temperatures of primer pairs were optimized to $55^{\circ} \mathrm{C}$ and (5) microsatellites were not compound or interrupted. We selected a subset $(\mathrm{n}=54)$ of sequences for which primers were designed for PCR amplification.

Total DNA was extracted from adult female mites with DNeasy 96 Blood and Tissue kit (Qiagen ${ }^{\circ}$ ). PCR amplifications were initially performed on eight individuals for each of the 54 primer pairs in a total volume of $10 \mu \mathrm{L}$ containing $2 \mu \mathrm{L}$ of DNA extract using the Multiplex PCR Kit (Qiagen ${ }^{\circ}$ ). Thermocycling was performed on a Mastercycler ${ }^{\circ}$ gradient (Eppendorf) with the following protocol: $95^{\circ} \mathrm{C}$ for $15 \mathrm{~min}$, followed by 35 cycles $\left(94^{\circ} \mathrm{C}\right.$ for $30 \mathrm{~s}$, $55^{\circ} \mathrm{C}$ for $90 \mathrm{~s}, 72^{\circ} \mathrm{C}$ for $1 \mathrm{~min}$ ), and $60^{\circ} \mathrm{C}$ for $30 \mathrm{~min}$. Out of the 54 primer pairs, 42 displayed clear PCR products on agarose gel electrophoresis, i.e. discrete single bands or at most two bands when there were large differences in size between alleles. The remaining 12 primer pairs either did not amplify in some of the 8 individuals or produced multiple bands or smears. The loci were amplified separately using forward primers labelled with the fluorescent dyes 6-FAM, PET, NED or VIC (Applied Biosystems). The PCR products were visualized using an ABI 3130XL Genetic Analyzer (Applied Biosystems). Allele sizes were scored against an internal GeneScan-500 LIZ $^{\circ}$ Size Standard (Applied Biosystems) and genotypes obtained using GeneMapper 3.7 (Applied Biosystems).

Among the 42 screened markers, 14 showed unambiguous genotype patterns and were kept and amplified into three PCR multiplex kits in combination with 10 primers pairs previously described $[9,4,13]$ (Table 1 ). The three multiplex sets were tested using the amplification protocol described above.

The microsatellite kits successfully amplified 686 individuals from 60 populations originating from a wide geographical range (localities in the Northern Mediterranean basin), what highlights the potential usefulness for population genetic studies. The number of alleles per locus ranged from 3 to 16 and expected heterozygosity values ranged from 0.12 to 0.81 (Table 1). Most of the loci were not at Hardy-Weinberg equilibrium and showed a significant excess of homozygotes, a feature frequently perceived in field populations of T. urticae (e.g. [4, 14]). This can be explained by the biology of T. urticae, which is an arrhenotokous species [15] (diploid females produce haploid males from unfertilized eggs) what tends to form new colonies from very small propagule sizes and often from a single mated female. Each microsatellite locus characterized in this paper can be mapped on the T. urticae genome, what makes it of particular interest for further quantitative genetics applications. 
Table 1 Characterization and levels of variability at $\mathbf{2 4}$ microsatellite loci of Tetranychus urticae

\begin{tabular}{|c|c|c|c|c|c|c|c|c|c|c|}
\hline Locus & Motif & Primer sequence $\left(5^{\prime}-3^{\prime}\right)$ & $\begin{array}{l}\text { Scaffold } \\
\text { number }\end{array}$ & $\begin{array}{l}\text { Number } \\
\text { of set }\end{array}$ & Dye & $\begin{array}{l}\text { GenBank } \\
\text { accession No }\end{array}$ & $\begin{array}{l}\text { Size } \\
\text { range }\end{array}$ & $\mathrm{Na}$ & Ho & $\mathrm{He}$ \\
\hline \multirow[t]{2}{*}{ TuLS14 } & $(\mathrm{ATG}) 7$ & F: GCAAATGAAGCTTACCAATTA & 17 & 2 & VIC & KJ545959 & $191-210$ & 7 & 0.2 & 0.60 \\
\hline & & R:TAAAGGTTTGGCAGTTCAGT & & & & & & & & \\
\hline \multirow[t]{2}{*}{ TuLS16 } & (CAT) 10 & F: AATTGCTTATCACCCACATC & 21 & 2 & PET & KJ545960 & $186-228$ & 16 & 0.39 & 0.79 \\
\hline & & R:TTAGTTGCTTGTTGAGCAGA & & & & & & & & \\
\hline \multirow[t]{2}{*}{ TuLS17 } & (ATG)6 & F:TCTTCGTTCGATAGCTTTTC & 23 & 2 & FAM & KJ545961 & $192-207$ & 6 & 0.03 & 0.55 \\
\hline & & R:TCCTCAGGTATATCAGGTGG & & & & & & & & \\
\hline \multirow[t]{2}{*}{ TuLS19 } & $(\mathrm{TG}) 6$ & FCAAAAGTTGGACATTTCAGG & 24 & 2 & NED & KJ545962 & $195-211$ & 8 & 0.28 & 0.71 \\
\hline & & R:TCCTTCCACAGTCAATATCC & & & & & & & & \\
\hline \multirow[t]{2}{*}{ TuLS20 } & $(\mathrm{TTG}) 6$ & F: AAGCTGGATTCATAGAAGCA & 27 & 1 & PET & KJ545963 & $212-218$ & 3 & 0.16 & 0.38 \\
\hline & & R: AAATTAATTCAGCCTCGTCA & & & & & & & & \\
\hline \multirow[t]{2}{*}{ TuLS22 } & (TG)6 & F: GCAATCGTTTGTTTTCATTT & 33 & 1 & NED & KJ545964 & $191-203$ & 5 & 0.17 & 0.43 \\
\hline & & R: TCACAATTGATGATGCTTGT & & & & & & & & \\
\hline \multirow[t]{2}{*}{ TuLS23 } & $(\mathrm{TAA}) 6$ & F:TGGTAACTGCATCAACCATA & 34 & 3 & PET & KJ545965 & 193-202 & 4 & 0.21 & 0.66 \\
\hline & & R: AAGATTCGGGAAGATTAAGG & & & & & & & & \\
\hline \multirow[t]{2}{*}{ TuLS24 } & $(\mathrm{GA}) 7$ & F:TGTTGTATGGGAATAAGACAAG & 36 & 3 & VIC & KJ545966 & $225-238$ & 10 & 0.26 & 0.69 \\
\hline & & R: GTGATTGGCCTGATAATGTT & & & & & & & & \\
\hline \multirow[t]{2}{*}{ TuLS35 } & (TG)8 & F: GGAAACGTATCACAATTTGG & 100 & 2 & FAM & KJ545967 & 204-292 & 8 & 0.17 & 0.70 \\
\hline & & R AGAATCTTTTGTTGCTTCCA & & & & & & & & \\
\hline \multirow[t]{2}{*}{ TuLS38 } & $(\mathrm{CAA}) 6$ & F: CAACACCAATCACAAAATGA & 15 & 1 & NED & KJ545968 & $239-253$ & 5 & 0.03 & 0.13 \\
\hline & & R: GTTGGACTTGGTGAATCAGT & & & & & & & & \\
\hline \multirow[t]{2}{*}{ TuLS39 } & $(A G C) 6$ & F: ACATTATCGTTCGGTTCATC & 17 & 3 & VIC & KJ545969 & $270-293$ & 7 & 0.04 & 0.15 \\
\hline & & R: CTTTGTTCCCTTTTATGTGC & & & & & & & & \\
\hline \multirow[t]{2}{*}{ TuLS41 } & (CAT)6 & F: GAATGAAGATTGGTGGGTTA & 23 & 3 & PET & KJ545970 & $242-261$ & 8 & 0.27 & 0.53 \\
\hline & & R: TCAAGATTTTGGAATCAGAGA & & & & & & & & \\
\hline \multirow[t]{2}{*}{ TuLS42 } & (ATC) 5 & F:TTCCTCTTCCTTGTCTTTCA & 27 & 3 & FAM & KJ545971 & $230-269$ & 10 & 0.07 & 0.52 \\
\hline & & R: CATCATCTTGTTGTTTGTGC & & & & & & & & \\
\hline \multirow[t]{2}{*}{ TuLS43 } & (GAT)5 & F: AATGGAGGTATGGATGACG & 28 & 3 & NED & KJ545972 & $262-277$ & 4 & 0.02 & 0.14 \\
\hline & & R: AAAGCTGCTGAAAGTCACTC & & & & & & & & \\
\hline \multirow[t]{2}{*}{ Tupm07* } & $(\mathrm{CT}) 10$ & F: CCAATCACTGTGTTGATCGC & 13 & 3 & NED & na & $79-94$ & 10 & 0.43 & 0.71 \\
\hline & & R: GGCTGGTTTCTCTTTCTCCC & & & & & & & & \\
\hline \multirow[t]{2}{*}{ Tupm08* } & $(\mathrm{AG}) 10$ & FAAGCAACAGTTTAGGATGAGAAGG & 16 & 2 & PET & na & $78-92$ & 8 & 0.33 & 0.81 \\
\hline & & R: AGTCCATCTTCCTCTTGTCTTCTAGT & & & & & & & & \\
\hline \multirow[t]{2}{*}{ Tupm09* } & $(\mathrm{CT}) 10$ & F:TGAAAAGCGAAACATTGATTCTA & 6 & 3 & FAM & na & $74-91$ & 8 & 0.31 & 0.80 \\
\hline & & R: GAAATGTCGAGTTGTCAGGG & & & & & & & & \\
\hline \multirow[t]{2}{*}{ TuCA12* } & $(C A) 7$ & F: GATTTGTGGTCGTGGTTTTC & 9 & 1 & FAM & AB263078 & $177-287$ & 15 & 0.23 & 0.78 \\
\hline & & R: GATCAACTCAAAAGGATAACGTTG & & & & & & & & \\
\hline \multirow[t]{2}{*}{ TuCA83* } & (GT)6 & F: CAGGGTGAAACTTAGATACC & 2 & 1 & VIC & AB263081 & $201-219$ & 11 & 0.24 & 0.74 \\
\hline & & R: CAATTTTCCCTCTACATCTC & & & & & & & & \\
\hline TuCA96* & (TG)7 & F: ATGGATTGTCACCGATTTCA & 11 & 1 & PET & AB263082 & $109-218$ & 4 & 0.10 & 0.60 \\
\hline & & R: CTGAAGTTTACTTGCTATAGTC & & & & & & & & \\
\hline TuCT09* & (CT)15 & F: GATCACTTTTTCATGTTATTCTG & na & 2 & FAM & AB263084 & $108-118$ & 7 & 0.08 & 0.53 \\
\hline & & R: CTTGGAATGAACTTTAGCAC & & & & & & & & \\
\hline TuCT67* & $(\mathrm{CT}) 9$ & F: CCATCATCTTCATCATTCTTCACC & 9 & 2 & NED & AB263090 & $88-112$ & 15 & 0.21 & 0.73 \\
\hline & & R:TAGAACAGTCAAGCAAAAAGAGTC & & & & & & & & \\
\hline TuCT73* & $(C A) 7$ & F: CGATGTGGGTGGTAAGCATG & 18 & 1 & VIC & AB263091 & $106-214$ & 9 & 0.25 & 0.69 \\
\hline & & R: ACGATGATATTGATGATGAGCG & & & & & & & & \\
\hline Tu35b* & $(\mathrm{TGA}) 8$ & F: CTTCCCGAAGGCTGTTGATA & 1 & 1 & NED & AJ419832 & $91-113$ & 6 & 0.22 & 0.40 \\
\hline & & R: AATGGAATGAGTTATCGTTGGG & & & & & & & & \\
\hline
\end{tabular}

The scaffold number is given as indicated in the annotated whole genome of $T$. urticae and can be retrieved at ORCAE [16]."Na" is the number of alleles. Observed heterozygosities (Ho) Expected heterozygosities (He) calculated with ADEgenet R package [17].

* Loci published previously. 


\section{Data accessibility}

DNA sequences: Genbank accessions KJ545959 to KJ545972; AB263078-AB263081-AB263082-AB263084-AB263090AB263091 and AJ419832.

Genome data: Individual scaffolds of the T. urticae (London) genome are available through GenBank under accession numbers HE587301 to HE587940.

\section{Abbreviations}

MtDNA: Mitochondrial DNA; DOE-JGI: Department of Energy Joint Genome Institute; Mb: Megabase; Kb: Kilobase; Bp: Base pair; PCR: Polymerase chain reaction; $\mu \mathrm{L}$ : Microliter.

\section{Authors' contributions}

LS carried out the molecular genetics laboratory work. LS and MN drafted the manuscript. MN conceived the study, obtained funding for the work and prepared the manuscript jointly with LS. AM, PA and SF sampled biological material. JEL performed the statistical analyses. All authors read, contributed to and approved the final manuscript.

\section{Acknowledgements}

We thank Stephane Rombauts from the VIB Department of Plant Systems Biology, UGent, Belgium, for providing files with repeated motifs sequences and Miodrag Grbic from the University of Western Ontario, London, Canada, for his contribution as leader of the T. urticae whole genome project. We thank Elodie Flaven for technical advice at an early stage of project. Data used in this work were (partially) produced through molecular genetic analysis technical facilities of the labex "Centre Méditerranéen de l'Environnement et de la Biodiversité" Funding was provided by the French Agence Nationale de la Recherche, grants to MN: ANR 2010 BLAN 171502 and ANR-14-JFAC-0006-01. This work beneficiated from information retrieved from the genome and transcriptome sequencing projects which were funded by the Government of Canada through Genome Canada and the Ontario Genomics Institute (OGl046), JGl Community Sequencing Program grant 777506 to M. Grbic. This work was supported by the Metaprogramme Adaptation of Agriculture and Forest to Climate Change (AAFCC) of the French National Institute for Agricultural Research (INRA)

\section{Compliance with ethical guidelines}

\section{Competing interests}

The authors declare that they have no competing interests.

Received: 18 April 2014 Accepted: 20 May 2015

Published online: 17 June 2015

\section{References}

1. Spider Mites Web: a comprehensive database for the Tetranychidae (http://www.montpellier.inra.fr/CBGP/spmweb)

2. Navajas M, Lagnel J, Gutierrez J, Boursot P (1998) Species wide homogeneity of nuclear ribosomal ITS2 sequences in the spider mite Tetranychus urticae contrasts with extensive mitochondrial COI polymorphism. Heredity $80: 742-752$
3. Navajas MJ, Thistlewood HMA, Lagnel J, Hughes C (1998) Microsatellite sequences are under-represented in two mite genomes. Insect Mol Biol 7:249-256

4. Navajas M, Perrot-Minnot MJ, Lagnel J, Migeon A, Bourse T, Cornuet JM (2002) Genetic structure of the greenhouse population of the spider mite Tetranychus urticae: spatio-temporal analysis with microsatellite markers. Insect Mol Biol 11:157-165

5. Sabater-Munoz B, Pascual-Ruiz S, Gomez-Martinez MA, Jacas JA, Hurtado MA (2012) Isolation and characterization of polymorphic microsatellite markers in Tetranychus urticae and cross amplification in other Tetranychidae and Phytoseiidae species of economic importance. Exp Appl Acarol 57:37-51

6. Sun JT, Lian C, Navajas M, Hong XY (2012) Microsatellites reveal a strong subdivision of genetic structure in Chinese populations of the mite Tetranychus urticae Koch (Acari: Tetranychidae). BMC Genetics 13:8. doi:10.1186/1471-2156-13-8

7. Carbonnelle S, Hance T, Migeon A, Baret P, Cros-Arteil S, Navajas M (2007) Microsatellite markers reveal spatial genetic structure of Tetranychus urticae (Acari : Tetranychidae) populations along a latitudinal gradient in Europe. Exp Appl Acarol 41:225-241

8. Aguilar-Fenollosa E, Pina T, Gomez-Martinez MA, Hurtado MA, Jacas JA (2012) Does host adaptation of Tetranychus urticae populations in clementine orchards with a Festuca arundinacea cover contribute to a better natural regulation of this pest mite? Entomol Exp Appl 144:181-190

9. Uesugi R, Sasawaki T, Osakabe M (2009) Evidence of a high level of gene flow among apple trees in Tetranychus urticae. Exp Appl Acarol 49:281-290

10. Grbic M, Van Leeuwen T, Clark RM, Rombauts S, Rouze P, Grbic V et al (2011) The genome of Tetranychus urticae reveals herbivorous pest adaptations. Nature 479:487-492

11. Meglecz E, Costedoat C, Dubut V, Gilles A, Malausa T, Pech N et al (2010) QDD: a user-friendly program to select microsatellite markers and design primers from large sequencing projects. Bioinformatics 26:403-404

12. Ge C, Sun JT, Cui YN, Hong XY (2013) Rapid development of 36 polymorphic microsatellite markers for Tetranychus truncatus by transferring from Tetranychus urticae. Exp Appl Acarol 26:195-212

13. Bitume EV, Bonte D, Ronce O, Bach F, Flaven E, Olivieri I et al (2013) Density and genetic relatedness increase dispersal distance in a subsocial organism. Ecol Lett 16:430-437

14. Tsagkarakou A, Navajas M, Papaioannou-Souliotis P, Pasteur N (1998) Gene flow among Tetranychus urticae (Acari: Tetranychidae) populations in Greece. Mol Ecol 6:305-314

15. Helle W, Bolland HR (1967) Karyotypes and sex-determination in spider mites (Tetranychidae). Genetica 38:43-53

16. Sterck L, Billiau K, Abeel T, Rouze P, van de Peer Y (2012) ORCAE: online resource for community annotation of eukaryotes. Nat Methods 9:1041

17. Jombart T, Ahmed I (2011) Adegenet 1.3-1: new tools for the analysis of genome-wide SNP data. Bioinformatics 27:3070-307

\section{Submit your next manuscript to BioMed Central and take full advantage of:}

- Convenient online submission

- Thorough peer review

- No space constraints or color figure charges

- Immediate publication on acceptance

- Inclusion in PubMed, CAS, Scopus and Google Scholar

- Research which is freely available for redistribution

Submit your manuscript at www.biomedcentral.com/submit
( Biomed Central 